\title{
Students’ Perception and Experiences of A Programme with Cultural and Adventure Initiatives Towards Group Cohesion
}

\author{
Charl J. Roux \\ University of Johannesburg, Johannesburg, South Africa \\ Natasha Janse van Rensburg \\ Vaal University of Technology, Vanderbijlpark, South Africa
}

\begin{abstract}
The purpose of this exploratory study was to determine the influence of selected cultural and adventure initiatives on the perception and experiences of group cohesion in a multicultural higher education institution. After a 3-day camp, rich qualitative data from students $(n=120)$ were gathered through focus group discussions and PowerPoint presentations. Using ATLAS.ti, four themes emerged: positive attitude and behaviour, maintaining group level, self-maintaining, and membership attraction and attachment. The findings revealed positive experiences among the participants. It is recommended that follow-up interventions should follow to ensure sustainability.
\end{abstract}

Keywords: group cohesion, cultural and adventure initiatives, multicultural higher education institutions

\section{Introduction}

It is evident that students may experience a number of factors, such as financial difficulties, transition from high school to higher education institutions (HEIs), peer pressure/influence and the multicultural environment, as negatively related to their academic performance and achievement. HEIs in South Africa report dismal student graduation rates as a norm. The South African survey 2002-2003 revealed that South Africa has the highest number of higher education students in sub-Saharan Africa, but that less than two students in every 10 actually graduate (Page, Loots, \& Toit, 2005). Although peer influence is one factor that negatively affects academic performance, it is evident that students also receive support from their peers or have learned that they can seek help from their peers (Fakude, 2012). Peer group is, therefore, an important agent of socialization (Senécal, Loughead, \& Bloom, 2008) into the multicultural HEI. It is generally accepted that games and similar initiatives can play a significant role in the socialization of people (Roux, Burnett, \& Hollander, 2008).

\section{Literature Review}

Acquisition of knowledge, skills, and attitudes is uniquely structured in different societies through formal (teaching and learning) and informal transfer. Socialization, the active life-long process of learning and social interaction through which people acquire personality and learn the ways of the society they live in, is embedded in diverse and multi-level domains (Coakley, 2004; Coakley \& Burnett, 2014). Social learning theory (the formation of identity as a learned response to social stimuli) emphasizes the social context of socialization

Charl J. Roux, Associate Professor, Sport and Movement Studies, Faculty of Health Sciences, University of Johannesburg. Email: croux@uj.co.za.

Natasha Janse van Rensburg, Lecturer, Marketing and Sport Department, Faculty of Management Sciences, Vaal University of Technology. 
where behaviours and attitudes develop in response to reinforcement and encouragement from those around them (Bandura \& Walters, 1963; Bandura, 1977).

Group cohesion is a dynamic process where group members tend to remain together in the pursuit of common purpose and goals. Groups have characteristics that are common to them (Eys, Burke, Carron, \& Dennis, 2006). A group has common fate to its members, a mutual benefit for members, social structure, group processes, and self-categorization (Hall, 2007). Social cohesion is the degree to which members of a group like each other and receive personal satisfaction from each other's presence (Cox, 2006). A group's cohesion can include either task cohesion, social cohesion, or both (Hall, 2007). Social cohesion is defined as when participants spend time together or share common interests outside the common purpose of the group; task cohesion is where group members unite to accomplish a specific task. People participating with others in recreation and adventure activities will gain the most psychological, physical, emotional, and spiritual benefits (O’Connell \& Cuthbertson, 2009). Social cohesion is, therefore, a topic of interest in sociology, psychology, mental health, and most recently, in public health.

A methodology developed for an experimental study (Roux, 2000) involved the implementation of an intervention programme, with the objective of changing attitudes and perceptions towards the "self" and "others" to improve group cohesion and dynamics (team functioning). Due to the significant positive changes $(p<0.01)$ in attitude, it was concluded that the intervention programme had a positive effect on the attitude of the participants (Roux, 2002). Therefore, we decided to adapt and use this methodology during a 3-day camp with second-year university students. The main aim of this study was to determine their perceptions about a programme of selected adventure and cultural initiatives towards group cohesion and dynamics in a multicultural setting, the University of Johannesburg. This is important for fostering positive interpersonal relationships and tolerance towards others within their own ethnic group and, especially, people from other ethnic groups. This positive experience could have a positive impact on the life, personal development, and academic achievements of these participants (Roux, 2002).

\section{Methods and Procedures}

This explorative qualitative research included all second-year students $(n=120)$ from the Department of Sport and Movement Studies, University of Johannesburg. The participants were grouped $(n=10)$ according to gender and race, to represent the demographics of the university student body as accurately as possible. As the programme progressed, the participants provided reflection and feedback about their experience of the various programme activities.

\section{Data Collection}

Debriefing sessions were conducted after every activity and a final focus group discussion was conducted a week after the camp. Each group had to prepare a PowerPoint presentation and provide feedback by verbally reflecting on:

(1) The content of the activities in the programme;

(2) Their experience while participating in these activities;

(3) Their feelings about their counterparts' input during these activities;

(4) Their purpose in the bigger group, i.e., the second-year group, as well as being a student at the university;

(5) How typical or similar activities could be used to assimilate real-life situations. 
Participants were invited to take part and informed about the aims and proceedings of the research. On formal agreement, sessions were audio-tape recorded. Participants were given the opportunity to withdraw from the session at any time, if they wished. Each session lasted between 30 and 40 minutes. Groups were coded Grp A-J. The information from both the PowerPoint presentation and the audio-tape recordings was analyzed with ATLAS.ti. Themes and subthemes were identified and discussed.

\section{Researchers and Facilitators}

An independent researcher, trained in the methodology, administered the research and collected the data during the focus group discussion sessions. The facilitators were trained before the camp on the execution of the activities, how to create teaching moments to address various values, and how to plan and conduct a debriefing session.

\section{Intervention Activities and Sequencing}

The activities for this 3-day intervention programme were specifically chosen with the objective of changing the perceptions of the participants towards themselves, their circumstances, and their peers. A prerequisite for success of the programme is the specific sequence in which the activities are presented. The sequencing (Tuckman, 1965; Bunting, 1985) was adapted from and based on the model developed by Roux (2002) (see Figure 1).

According to Tuckman (1965), groups go through five stages: forming, storming, norming, performing, and adjourning. To promote group cohesion among the students, only the first four stages were applicable. In the forming stage, relationships are formed. Groups then go through the storming stage, associated with confusion or arguments; thereafter, the group will use the norming stage to set rules guiding them to the performing stage. This final stage is best associated with group cohesion.

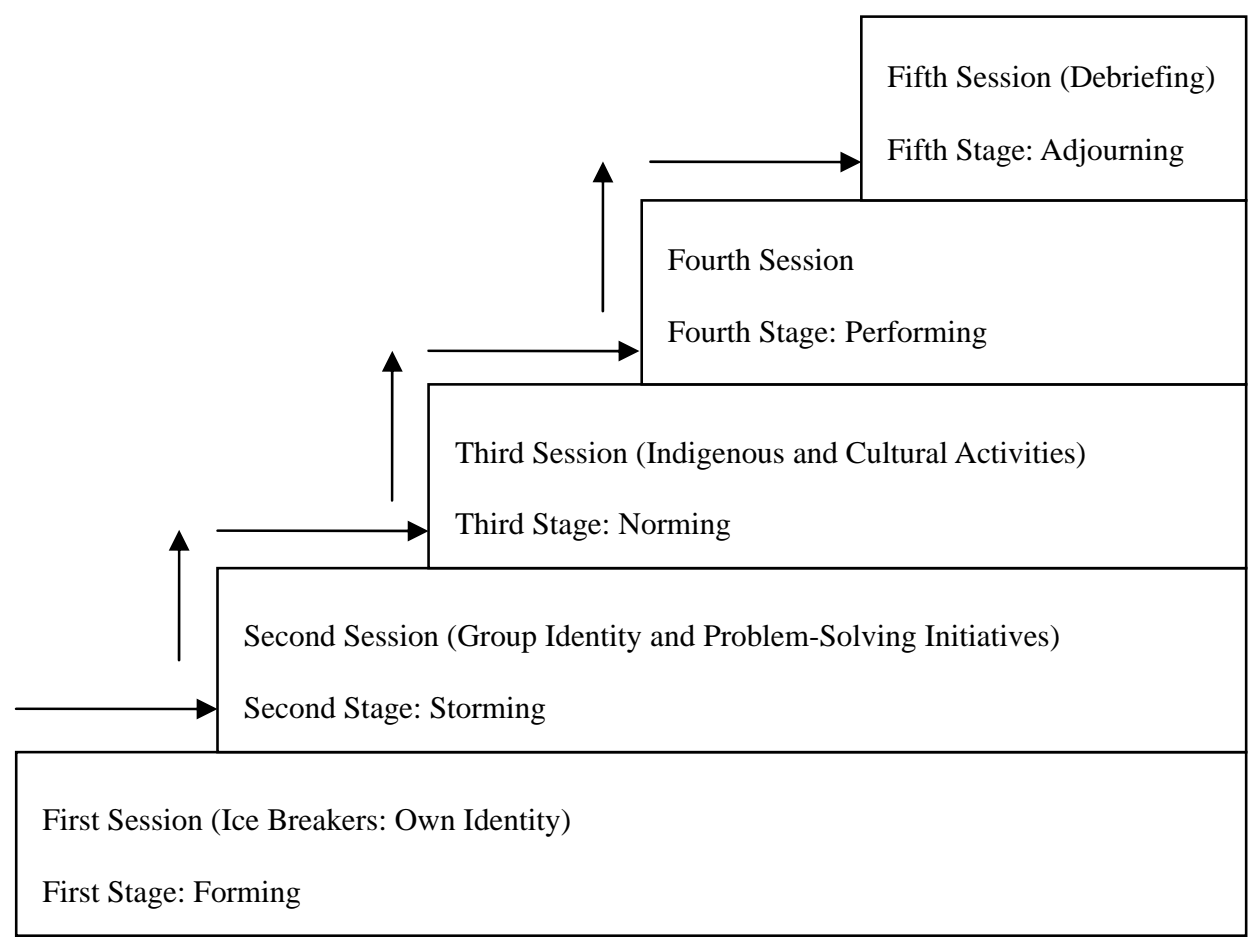

Figure 1. The sequencing of activities from Tuckman (1965) and Bunting (1985). 


\section{Intervention Programme}

First session (Ice breakers: own identity): Day 1. The aim of these activities was to facilitate communication skills, trust, and commitment. This was enabled by the participants introducing themselves and sharing personal feelings, ideas, and experiences with other group members, to effectively work together as a team with a common goal of winning the other teams (Roux, 2002):

(1) The know-yourself activity;

(2) Human knot;

(3) Relay games.

Debriefing. A debriefing session was organized immediately afterwards to discuss feelings and experiences encountered during the session.

Second session (Group identity and problem-solving initiatives): Days 1 and 2. The aim of this session was to develop a group identity (unity of diversity), to identify the group’s purpose and vision, as well as to plan, and to communicate individual roles and leadership skills:

(1) T-shirts;

(2) Posters;

(3) Potjie-kos.

Debriefing. This session was concluded with a debriefing session. This comprised a brief discussion on the content of the session activities and the experience of group members while participating in them. It also provided the opportunity for group members to explain their feelings about their counterparts' contributions towards the completion and outcomes of the activities.

Third session (Indigenous and cultural activities): Day 2. The aims of this session were interaction, fostering understanding and awareness, celebrating diversity within a multicultural society, and identifying similarities within and among cultural groups. Each activity was introduced with a brief background narrative and a description of how to execute the activity. The participants also had to learn to sing an Afrikaans folksong "Ek soek na my Dina" before an accompanying dance was introduced:

(1) Dibeke;

(2) Ek soek na my Dina (Folk dance);

(3) Rotte Ei (Rotten Egg).

Debriefing. The content of the activities from this session was discussed in detail. The participants had to discuss the positives and negatives they had experienced while singing and dancing "Ek soek na my Dina", and playing "Dibeke". The participants had to reflect on positive involvement evident from other participants within their own group $(n=10)$. The participants were asked to stand up during a meeting with the whole group ( $n=120$ ), to call that person by name, to tell the group what this person has done to deserve praise, and to congratulate this person with a hug.

Fourth session (Obstacle course and concert): Day 2. The aim of this session was to develop the following competencies: planning, brainstorming, identification of talents, ordering of ideas and imagining alternatives, interaction skills, communication skills, leadership skills, and performing with other people in front of an audience: 
(1) Obstacle course. The aim of this activity was to reach for individual as well as team-oriented outcomes. While an individual attempted a challenge on the equipment, the other participants remained on the ground acting as spotters and encouragers. It was expected that group members support one another physically and emotionally (Prouty, Panicucci, \& Collinson, 2007). Although the groups were competing for the best time, safety, support and cooperation were key factors. Therefore, the time of the person who finished last in each group was taken as the official time for the group. The obstacle course could only accommodate two teams at a time, and these were determined by drawing the same number from a hat. During the race, the rest of the group could choose a favourite competitor to support. All 120 study participants were involved;

(2) Concert (role play). A concert with role play was organized, with the theme "What is wrong with this picture?”. The aims were to help participants develop a sense of aesthetic understanding, to explore emotions, to gain confidence in their own abilities, to learn respect and depend on others, to appreciate the values and attitudes of their own and other communities, and to develop group dynamic skills (Taylor, 1991). The play was staged in front of all students and staff $(n=133)$ at the camp.

Debriefing. This debriefing session was similar to previous sessions. However, for the last two activities, the participants had good interaction with the total group. Participants were asked to call upon any participant from any group to stand up, so they could be praised and hugged for their performance, attitude, and contribution towards the success of the camp. The session was concluded with a prize-giving ceremony and free social interaction.

\section{Results and Discussion}

Four main themes emerged from the analysis of the PowerPoint presentations and the focus group discussions (see Table 1). These themes were further divided into subthemes.

Table 1

Overview of Main Themes and Subthemes

\begin{tabular}{|c|c|}
\hline Main themes & Subthemes \\
\hline 1. Positive attitudes and behaviours & $\begin{array}{l}\text { Positive attitudes and behaviours contributing towards group } \\
\text { cohesion: } \\
\text { (1) Respect for the team } \\
\text { (2) Good attendance/punctuality } \\
\text { (3) Taking responsibility } \\
\text { (4) Being friendly } \\
\text { (5) Being willing or available }\end{array}$ \\
\hline 2. Maintaining group level & $\begin{array}{l}\text { Primary interpersonal interactions to keep group operating } \\
\text { cohesively: } \\
\text { (1) Constant communication } \\
\text { Secondary interpersonal interactions: } \\
\text { (1) Exchange of information } \\
\text { (2) Exchange of feelings }\end{array}$ \\
\hline 3. Self-maintaining & $\begin{array}{l}\text { How group cohesion is maintained by independent effort: } \\
\text { (1) Level of effort } \\
\text { (2) Skills and knowledge } \\
\text { (3) Performance strategies }\end{array}$ \\
\hline 4. Membership attraction and attachment & $\begin{array}{l}\text { Components contributing to lasting group cohesion: } \\
\text { (1) Interpersonal expectations } \\
\text { (2) Emotional bond } \\
\text { (3) Control or leadership } \\
\text { (4) Affiliation }\end{array}$ \\
\hline
\end{tabular}




\section{Theme 1: Positive Attitudes and Behaviours}

During the presentation, the groups explained how positive attitudes and behaviours contributed to their group cohesion. The most recurrent behaviour expressed by participants was respect. Other behaviours or attitudes included the willingness of group members, members taking responsibility, and friendliness or members being nice. Only a few groups reported on positive behaviour, specifically on good attendance and availability to assist.

“... The camp provides us with life-long skills that will help us in our daily lives. We learnt social skills where everyone agrees to co-operate and respect each other and for us to practice decision making...” (Grp E)

“... I found the best activity was the obstacle course as that truly tested each group's compatibility and willingness to work together...” (Grp C)

“... On this positive camp, everyone was friendly and there was no drama amongst students...” (Grp E)

The relationship between group cohesion and respect was confirmed (Thompson, Kray, \& Lind, 1998; Williams, 2001) and it was evident that groups received better long-term results from forming a respect-based identity. At HEIs, students need to foster respect for self and others, regardless of race or gender (Cross, 2004). Group cohesion is the willingness to be part of the group and to be available to support when needed (Friedkin, 2004). A positive attitude towards the group is perceived by a willingness to take on more responsibility than needed (Wright \& Lander, 2003). Friendliness and “just being nice” is underestimated, especially in the formation of groups (Todd \& Nesdale, 1997).

\section{Theme 2: Maintaining Group Level}

The groups consistently referred to a crucial interpersonal method of interaction that affirms group cohesion: constant communication. The groups explained that the exchange of feelings and information happened both while participating in the activities and in the facilitated reflection sessions. One group mentioned the difficulty of voicing negative feelings during reflection sessions, yet commended the facilitator's support. The following quotes best represent this theme:

“... Communicating with the team. Social rules and relations are created, communicated, and changed in verbal and nonverbal ways...” (Grp F)

“... I have learned to respect one another, communicate if there is a problem, and I need to trust that no matter what life throws at me, they will be there to support me...” (Grp E)

“... The reflection sessions were quite challenging especially when we had to give a negative characteristic of one of our group mates - our group didn't answer this question, as we felt it was impossible to answer...” (Grp D)

Communication, verbal and nonverbal, plays an important role in maintaining group cohesion (Spoor \& Kelly, 2004) and is of utmost importance to accomplish common goals (Siebold, 2007). Good communication skills provide group members with the confidence to address issues or resolve conflict among themselves (Amos, Hu, \& Herrick, 2005). Conflict usually arises due to communication breakdowns, whereas constant communication creates a platform from which mutual understanding and trust are created.

\section{Theme 3: Self-maintaining}

Two methods to maintain group cohesion were frequently mentioned by the majority of the groups: (1) the specific knowledge and skills group members already had; and (2) different strategies they applied throughout the intervention programme. The level of effort from individuals was also mentioned during the discussions. 
“... Working collectively came with advantages such as making speedy decisions, being more creative due to the availability of more diversified views, accepting solutions to problems easier as well as the acquisition of complete and accurate information, which had an overall effect on the level of performance in every task...” (Grp B)

"... The obstacle course was the most fun for me as it really made us depend on each other to achieve the goal...” (Grp E)

To maintain group cohesion, groups should be interdependent and able to function without external support (Janz, Colquitt, \& Noe, 1997). Thus, codependence or interdependence is a crucial element in group cohesion, especially when a goal is being achieved (Conte \& Sichman, 2002). Interdependence can be reinforced by truly knowing group members, which includes knowing their strengths and weaknesses. This knowledge can only be useful if it is applied as a strategy towards goal achievement (P. R. Harris \& K. G. Harris, 1996; Zaccaro, Blair, Peterson, \& Zazanis, 1995).

\section{Theme 4: Strong Membership Attraction and Attachments}

For group cohesion to continue, the groups indicated specific aspects that contributed to stronger membership attraction and attachments. Many groups focused on interpersonal expectations and its role in group cohesion. Control within the group or leadership, affiliation to the group and emotional bonds within the group were also mentioned.

“... I am a bit of a control freak and I expect things to be done my way usually, however on the camp, I started becoming more relaxed with my group members and trusted them more and that is something I will take and implement in my life...” (Grp B)

“... I enjoyed the sense of belonging to a group and loved how we all got along so quickly and put our differences aside...” (Grp C)

For a group to be successful, members should experience strong attraction and attachment to it (Walter \& Bruch, 2008). Group attraction and attachment can be influenced by the level of affiliation with the group. Feeling united with or joined to the group may create a willingness to be controlled by other members (Wiltermuth \& Heath, 2009). For group cohesion, each group member must be prepared to fulfill a dominating or submissive role voluntarily (Yalom \& Leszcz, 2005). This role (dominant or submissive) will only form naturally if the group feels a sense of belonging or unity (Overbeck, Correll, \& Park, 2005).

The results of this study may add significant value to the body of knowledge, especially for students in the South African context: "becoming friends with someone I thought of as my enemy”. It was evident that the programme contributed positively towards group cohesion among the participants "respecting people no matter their race or gender". It is expected that these students will apply this methodology with similar initiatives in real-life situations in their academic career and beyond. The majority of the groups had positive experiences and could already appreciate the applicability of lessons learned from camp to other areas in their life. Statements such as "feeling that I have known the group for a long time” and “... little did I know I just became a Bush Pirate" indicated that group cohesion and an overall positive experience were achieved. All the groups indicated that similar interventions should occur earlier in their academic career and more often, to assure sustainability (Roux et al., 2008). 


\section{References}

Amos, M. A., Hu, J., \& Herrick, C. A. (2005). The impact of team building on communication and job satisfaction of nursing staff. Journal for Nurses in Professional Development, 21(1), 10-16.

Bandura, A. (1977). Social learning theory. Englewood Cliffs, NJ: Prentice Hall.

Bandura, A., \& Walters, R. H. (1963). Social learning and personality development. New York, NY: Holt, Rinehart and Winston.

Bunting, C. J. (1985). Venture dynamics: The challenge course as an educational tool. Outdoor Education Institute, College Station, Texas University, Texas A\&M.

Coakley, J. J. (2004). Sport in society: Issues and controversies. Colorado Springs: Mosby.

Coakley, J. J., \& Burnett, C. (2014). Sport in society: Issues and controversies. Pretoria: Van Schaik Publishers.

Conte, R., \& Sichman, J. S. (2002). Dependence graphs: Dependence within and between groups. Computational \& Mathematical Organization Theory, 8(2), 87-112.

Cox, R. H. (2006). Sport psychology: Concepts and applications (6th ed.). New York, NY: McGraw-Hill.

Cross, M. (2004). Institutionalising campus diversity in South African higher education: Review of diversity scholarship and diversity education. Higher Education, 47(4), 387-410.

Eys, M. A., Burke, S. M., Carron, A. V., \& Dennis, P. W. (2006). The sport team as an effective group. In J. M. Williams (Ed.), Applied sport psychology: Personal growth to peak performance (5th ed.) (pp. 157-173). New York, NY: McGraw-Hill.

Fakude, X. S. (2012). A dissertation submitted for Master's Degree in Educational Psychology at the University of Zululand.

Friedkin, N. E. (2004). Social cohesion. Annual Review of Sociology, 30(1), 409-425.

Hall, A. (2007). Sport psychology: Building group cohesion, performance, and trust in athletic teams. Capella University.

Harris, P. R., \& Harris, K. G. (1996). Managing effectively through teams. Team Performance Management: An International Journal, 2(3), 23-36.

Janz, B. D., Colquitt, J. A., \& Noe, R. A. (1997). Knowledge worker team effectiveness: The role of autonomy, interdependence, team development, and contextual support variables. Personnel Psychology, 50(4), 877-904.

O’Connell, T. S., \& Cuthbertson, B. (2009). Group dynamics in recreation and leisure: Creating conscious groups through an experiential approach. Champaign, United States: Human Kinetics.

Overbeck, J. R., Correll, J., \& Park, B. (2005). Internal status sorting in groups: The problem of too many stars. In M. C. Thomas-Hunt (Ed.), Status and groups (Research on Managing Groups and Teams, Vol. 7, pp. 169-199). Emerald Group Publishing Limited.

Page, B. J., Loots, A., \& du Toit, D. F. (2005). Perspectives on a South African tutor/mentor program: The Stellenbosch University experience. Mentoring \& Tutoring: Partnership in Learning, 13(1), 5-21.

Prouty, D., Panicucci, J., \& Collinson, R. (Eds.). (2007). Adventure education: Theory and application. Champaign, United States: Human Kinetics.

Roux, C. J. (2000). The effect of selected cultural and initiative activities on the attitude of first year students towards ethnicity in a multicultural institution (Unpublished master's thesis, University of Stellenbosch, Stellenbosch).

Roux, C. J. (2002). Cultural dance and games initiatives as an intervention to change attitudes towards ethnicity in students. Journal of Human Movement Studies, 42, 167-184.

Roux, C. J., Burnett, C., \& Hollander, W. J. (2008). Curriculum enrichment through indigenous Zulu games. South African Journal for Research in Sport, Physical Education and Recreation, 30(1), 89-103.

Senécal, J., Loughead, T. M., \& Bloom, G. A. (2008). A season-long team-building intervention: Examining the effect of team goal setting on cohesion. Journal of Sport \& Exercise Psychology, 30(2), 186-199.

Siebold, G. L. (2007). The essence of military group cohesion. Armed Forces \& Society, 33(2), 286-295.

Spoor, J. R., \& Kelly, J. R. (2004). The evolutionary significance of affect in groups: Communication and group bonding. Group Processes \& Intergroup Relations, 7(4), 398-412.

Taylor, K. (1991). Drama strategies. New ideas from London drama. London: Heideman Educational Books Ltd..

Thompson, L., Kray, L. J., \& Lind, E. A. (1998). Cohesion and respect: An examination of group decision making in social and escalation dilemmas. Journal of Experimental Social Psychology, 34(3), 289-311.

Todd, P., \& Nesdale, D. (1997). Promoting intercultural contact between Australian and international university students. Journal of Higher Education Policy and Management, 19(1), 61-76.

Tuckman, B. W. (1965). Developmental sequence in small groups. Psychological Bulletin, 63(6), 384-399.

Walter, F., \& Bruch, H. (2008). The positive group affect spiral: A dynamic model of the emergence of positive affective similarity in work groups. Journal of Organizational Behavior, 29(2), 239-261.

Williams, M. (2001). In whom we trust: Group membership as an affective context for trust development. Academy of Management Review, 26(3), 377-396. 
Wiltermuth, S. S., \& Heath, C. (2009). Synchrony and cooperation. Psychological Science, 20(1), 1-5.

Wright, S., \& Lander, D. (2003). Collaborative group interactions of students from two ethnic backgrounds. Higher Education Research \& Development, 22(3), 237-251.

Yalom, I. D., \& Leszcz, M. (2005). Theory and practice of group psychotherapy. Basic books.

Zaccaro, S. J., Blair, V., Peterson, C., \& Zazanis, M. (1995). Collective efficacy. In Self-efficacy, adaptation, and adjustment (pp. 305-328). Springer US. 